\title{
Some Factors Affecting Structure, Transition Phase and Crystallized of CuNi Nanoparticles
}

\author{
Trong Dung Nguyen \\ Faculty of Physics, Hanoi National University of Education, Hanoi, Vietnam
}

Email address:

dungntsphn@gmail.com

To cite this article:

Trong Dung Nguyen. Some Factors Affecting Structure, Transition Phase and Crystallized of CuNi Nanoparticles. American Journal of Modern Physics. Vol. 6, No. 4, 2017, pp. 66-75. doi: 10.11648/j.ajmp.20170604.14

Received: May 24, 2017; Accepted: June 13, 2017; Published: July 17, 2017

\begin{abstract}
This paper studies the influence of atomic number at temperature of $300 \mathrm{~K}$, temperature at 5324 atoms, phase transition \& crystallization at different temperatures of $300 \mathrm{~K}, 500 \mathrm{~K}, 600 \mathrm{~K}, 700 \mathrm{~K}, 1100 \mathrm{~K}$ after $2 \times 10^{5}$ move steps number by increasing temperature of $4 \times 10^{12} \mathrm{~K} / \mathrm{s}$ on microstructure, phase transition temperature, phase transition \& crystallization of CuNi nanoparticle by molecular dynamics (MD) with embedded interaction Sutton-Chen and soft boundary conditions. Microstructure characteristics are analyzed through radial distribution function (RDF), energy, size, phase transition temperature (via relationship between energy and temperature), phase transition \& crystallization (via radial distribution function, $E_{t o t}$, move step number and common neighbor analysis (CNA)). Results show that first peak position of the radial distribution function is dominant; lengths of $\mathrm{Cu}-\mathrm{Cu}$, Ni-Ni with the results of Ni-Ni consistent with simulation. At $300 \mathrm{~K}$ temperature, nanoparticle appears in four phases namely FCC, HCP, ICO and Amorphous, presenting the effect of atomic number, temperature and move step number on microstructure, phase transition temperature and phase transition \& crystallization of CuNi nanoparticle.
\end{abstract}

Keywords: Atomic Number, Temperature, Move Step Number, Microstructure, Transition Temperature, Crystallization, CuNi Nanoparticle, Molecular Dynamics

\section{Introduction}

Nowadays, scientists continue to draw great attention to metal materials among which $[1,2]$ crystallized (Amorphous, crystalline) metal alloys are considered to be the most widely-used materials owing to abilities to increase magnetic, and their fields in material. In practice, crystalline material is formed after cooling material move from liquid to crystalline state. In 1960, Duwez et al created successfully amorphous material. [3] In 1976, Takayama fabricated amazingly $\mathrm{Ag}_{\mathrm{x}} \mathrm{Cu}_{1-\mathrm{x}} ; \mathrm{x}=0.35 \div 0.65$ alloy in amorphous state [4]. In 1999, Qi et al [35] produced excellently CuNi material in amorphous and liquid states by using fast-cooling method [ 23-26]. At that time, he argued that crystallization of alloy during tempering remained a very complex process involving microstructure etc. Since results of radial distribution function showed a great influence of heating rate, he also determined that heating rate ranged from $2 \times 10^{12} \mathrm{~K} / \mathrm{s}$ to $4 \times 10^{14} \mathrm{~K} / \mathrm{s}$, while atomic radius of $\mathrm{Cu}$ and $\mathrm{Ni}$ were $1.13 \AA$; $1.025 \AA$. However, he still could not explain effects of atomic density and others includingsize on the formation of the amorphous and crystal states [5]. Later in 2005, Q.X. Pei also fabricated successfully $\mathrm{CuNi}$ alloy at amorphous state structuring (FCC) with heating rate of $10^{6} \div 10^{12} \mathrm{~K} / \mathrm{s}$. Similarly, in 2013, E. L. de León-Quiroz et al. also investigated the effect of $\mathrm{Cu}_{1-\mathrm{x}} \mathrm{Ni}_{\mathrm{x}}$ impurity concentration on microstructure. [37] In 2016, Ramazan Oguzhan Aydin et al. studied phase transition of $\mathrm{CuNi}$ [38]. This study of $\mathrm{CuNi}$ materials, apart from empirical methods based on theoretical methods such as: The original principle, Ab Initio model [13] and molecular dynamics (MD) simulation method [14, 15, 16] with different interactions namely: Finnis-Sinclair [17], and Sutton-Chen [18, 19], is widely used to study alloys in liquid, and amorphous states [20-22]. Besides, Parrinello and Rahman also proposed the MD simulation method for NPT to study the effect of pressure on crystalline state of alloys of amorphous CuNi during heating. Recently, S. Kazanc has shown the second peak position of radial distribution function of $\mathrm{Cu}-\mathrm{Ni}$ alloys ranging at $3.62 \AA ; 3.60 \AA$ and $3.58 \AA$ at respectively pressures of 0 GPA, 3 GPA and 5 GPA. An 
increase of ressure reveals that second peak position of radial distribution function move gradually to the left [33]. Moreover, another report states that at the 0GPa second peak of radial is recorded at $3.6 \AA$ [34]. Similarly, relating to phase transition temperature, Yue Qi has determined a transition temperature at $550 \mathrm{~K}$ [35]. Nowadays, there are going-on minor studies on microstructure, phase transition \& crystallization of alloys of $\mathrm{CuNi}$ amorphous \& crystals by using MD method [9-12]. In order to increase understandings on crystalline and amorphous states [6-8] at micro level, this studyused molecular dynamics with embedded interactions Sutton-Chen [27-31] to investigate influences of factors including: atomic number, temperature, move step number on phase transferring process \& crystallization of $\mathrm{CuNi}$ nanoparticles.

Newly-found results not only provided insights on $\mathrm{CuNi}$ nanoparticles but also confirmed that an increase of atomic number in nanoparticle leads to a density of growing atoms (molecules), later an appearance of crystallization by lowering temperatures. However, a thorough understanding of microstructure formation in amorphous, and crystallization states of CuNi nanoparticles is still to be discovered. This paper only focuses on a study of the effect of atomic number, temperature, move step number on microstructure, phase transition temperature, crystallization process of $\mathrm{CuNi}$ nanoparticle. The calculations presented hereunder were performed at information technology room, Faculty of Physics, Hanoi National University of Education.

\section{Calculation Method}

Initially, nanoparticles (4000, 5324, 6912, 8788) atoms, were randomly seeded in a sphere by molecular dynamics $[16,20-22]$ with embedded interaction Sutten-Chen (1) [18, 19, 27-31] and aperiodic boundary conditions with,

$$
\begin{gathered}
E_{\text {tot }}=\varepsilon \sum_{i}\left(\frac{1}{2} \sum_{i \neq j} \Phi\left(r_{i j}\right)-C \sqrt{\rho_{i}}\right) \text { with } \Phi\left(r_{i j}\right)=\left(\frac{a_{i j}}{r_{i j}}\right)^{n}, \\
\rho_{i}=\sum_{i \neq j}\left(\frac{a_{i j}}{r_{i j}}\right)^{m}
\end{gathered}
$$

In it, the main parameters of the nanoparticle are:

Table 1. The Main Parameters of CuNi nanoparticle.

\begin{tabular}{llllll}
\hline Model & $\boldsymbol{\varepsilon}\left(\mathbf{. 1 0}^{-\mathbf{2}} \mathbf{e V}\right)$ & $\mathbf{a}(\AA)$ & $\mathbf{n}$ & $\mathbf{~ m}$ & $\mathbf{C}$ \\
\hline $\mathrm{Cu}$ & 0.57921 & 3.603 & 10 & 5 & 84.843 \\
$\mathrm{Ni}$ & 1.57070 & 3.520 & 9 & 6 & 39.432 \\
$\mathrm{CuNi}$ & 0.9538 & 3.5615 & 9.5 & 5.5 & 57.8405 \\
\hline
\end{tabular}

Coefficients of nanoparticle are defined as follows (2):

$$
\begin{gathered}
\varepsilon_{C u N i}=\sqrt{\varepsilon_{C u} \cdot \varepsilon_{N i}} ; a_{C u N i}=\frac{\left(a_{C u}+a_{N i}\right)}{2} ; n_{C u N i}=\frac{\left(n_{C u}+n_{N i}\right)}{2} ; \\
m_{C u N i}=\frac{\left(m_{c u}+m_{N i}\right)}{2} ; C_{C u N i}=\sqrt{C_{C u} \cdot C_{N i}}
\end{gathered}
$$

Among with: $r_{i j}$ is the distance between two atoms $i$ and $j$; a is network constant; $\rho_{i}$ is atomic density $i ; E_{\text {tot }}$ is energy of system; $\Phi\left(r_{i j}\right)$ is energy between two atoms $i$ and $j ; \varepsilon$ is energy; $\mathrm{C}, \mathrm{m}, \mathrm{n}$ are parameters of nanoparticle.

After having correspondings of nanoparticle CuNi (4000, $5324,6912,8788$ ) atoms, the nanoparticle were heated from 0 up to $2000 \mathrm{~K}$ with move step number $4 \times 10^{12} \mathrm{~K} / \mathrm{s}$ to break initial state of nanoparticle, then turned to liquid state. Cooled nanoparticle of liquid state descented from $2000 \mathrm{~K}$ to $300 \mathrm{~K}$ with move step number $4 \times 10^{12} \mathrm{~K} / \mathrm{s}$ for nanoparticle shifting from liquid to crystalline (amorphous, crystalline) states. The nanoparticles are studied on microstructure (through size, energy, radial distribution function), phase transition temperature (through relationship between temperature and energy), phase transition and crystallization (through radial distribution function, relationship between energy and move number, together with common neighbor analysis (CNA) [32]).

\section{Results and Discussion}

\subsection{The Influence of Atomic Number}

Obtained CuNi nanoparticles of (4000, 5324, 6912 and 8788 ) atoms with results of examined size and energy are shown in figures 1 and table 2 .

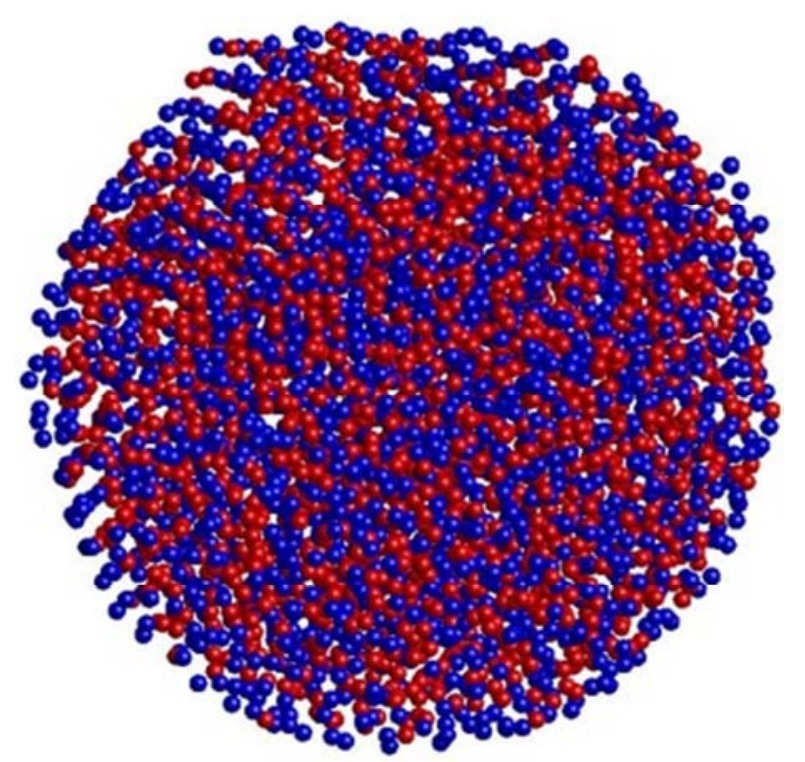

Figure 1. The Shape of CuNi Nanoparticle with 4000 Atoms (Red Cu, Blue $\mathrm{Ni}$ ).

Table 2. Size, Energy, Position and Heights of Radial Distribution Function of Nanoparticle CuNi with Different Atomic Numbers.

\begin{tabular}{llllll}
\hline \multirow{2}{*}{ Model } & \multicolumn{6}{l}{ Nano particles (atoms) } & \multirow{2}{*}{ Simulation } \\
\cline { 2 - 5 } & $\mathbf{4 0 0 0}$ & $\mathbf{5 3 2 4}$ & $\mathbf{6 9 1 2}$ & $\mathbf{8 7 8 8}$ & \\
\hline$r_{1}(\AA)$ & 2.48 & 2.44 & 2.46 & 2.44 & - \\
$r_{2}(\AA)$ & 3.62 & 3.58 & 3.56 & 3.48 & $3.62[33]$ \\
$\mathrm{g}_{1}(r)$ & 5.95 & 5.73 & 5.46 & 5.65 & - \\
$\mathrm{g}_{2}(r)$ & 0.66 & 0.623 & 0.54 & 0.56 & - \\
$\mathrm{d}(\mathrm{nm})$ & 13.46 & 14.81 & 16.15 & 17.49 & \\
$E_{\text {tot }}(\mathrm{eV})$ & -548.59 & -732.62 & -951.74 & -1215.74 & \\
\hline
\end{tabular}


Figure 1, table 2, shows $\mathrm{CuNi} 4000$ atomic nanoparticles at $300 \mathrm{~K}$ has spherical shapes, with two existing atoms of red $\mathrm{Cu}$ and blue $\mathrm{Ni}$, a size of $13.46 \mathrm{~nm}$. and an energy of $-548.59 \mathrm{eV}$. With an increase of atoms to 5324, 6912 and 8788, nanoparticles size also rises up to $14.81,16.15,17.49 \mathrm{~nm}$ with correspondence of energy of $-732.62,-951.74,-1215.74$ $\mathrm{eV}$ respectively. The results presents an increase of number of atoms in $\mathrm{CuNi}$ nanoparticles, then an enlargement of nanoparticles sizes, but a fall of energy of system.. This study of radial distribution function of $\mathrm{CuNi}$ nanoparticles confirms the above, as shown in figure 2 , table 2.

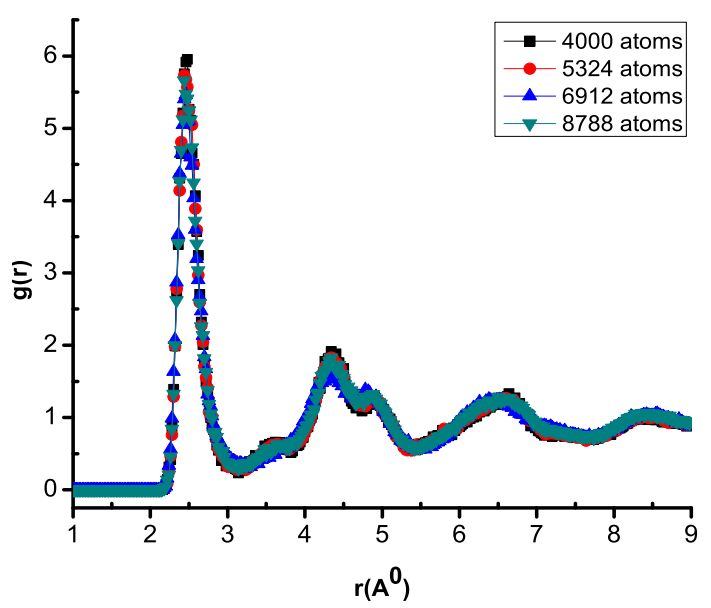

Figure 2. Radial Distribution Function of CuNi Nanoparticles with Different Atomic Numbers.

As results shown in figure 2 and table 2, nanoparticle $\mathrm{CuNi}$ at temperature of $300 \mathrm{~K}$ (Fig. 2) has the first peak position of the dominant radial distribution function. Increased in nanoparticle from 4000 up to 5324, 6912 and 8788, atoms show their first peak position of radial distribution function with an approximate negligibility of value change from $2.44 \AA$ to $2.48 \AA$, then the second onewith an enormous change of value from $3.48 \AA$ to $3.64 \AA$, in which, peak position at $r_{2}=3.62 \AA$ perfectly-matches with previous simulation at $3.62 \AA$ [33]; $3.6 \AA$ [34]. In addition, increasing number from 4000 up to 5324, 6912, 8788 atoms leads to high peak, while first peak radial distribution function of nanoparticle dropss from $5.95 \AA$ to $5.46 \AA$. This result shows that $\mathrm{CuNi}$ nanoparticle does not exist in far, but always do in near order.
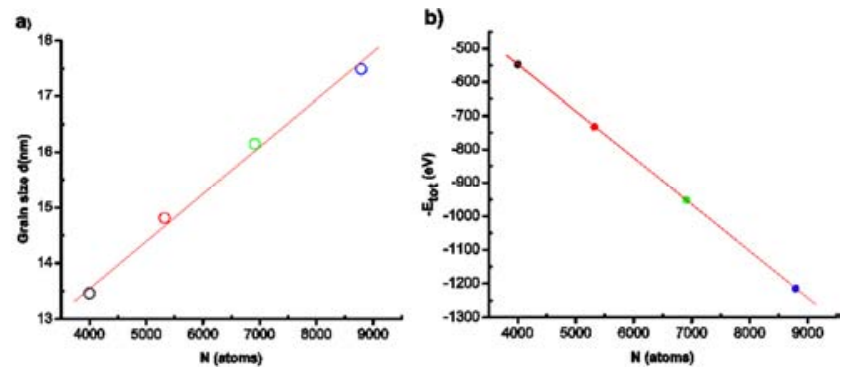

Figure 3. Relationship between d, $N$ (Fig. a), $E_{\text {tot, }} N$ (Fig. b).

Increasing atoms number lead to high peak, the first radial distribution function decreases resulting in an increase of atomic densities, as well as energy nanoparticle. Results in figure 3 show more about effect of particle size on atomic number, energy of system.

Figure 3 shows nanoparticles size (d) are always proportional with number of atoms $(\mathrm{N})$ in the form of $\mathrm{d}=$ 29.62 - $256.524 \mathrm{~N}^{-1 / 3}$ (Fig. 3a); Similarly with energy of system $\left(E_{t o t}\right)$ and $\mathrm{N}$ (Fig. 3b), $E_{\text {tot }}$ is proportional with N. At random, there is inter-dependence between $\mathrm{d}$ and $\mathrm{N}^{-1 / 3}$. Furthermore, CuNi nanoparticles appear with two formations of atoms of $\mathrm{Cu}, \mathrm{Ni}$, evenly distributed in nanoparticle. That raises a question: Whether the the linkage between atoms of $\mathrm{Ni}$, Cuexists in the nanoparticle of $\mathrm{Cu}-\mathrm{Cu}, \mathrm{Ni}-\mathrm{Ni}, \mathrm{Cu}-\mathrm{Ni}$. Results of this study of radial distribution functions of $\mathrm{Cu}$ $\mathrm{Cu}, \mathrm{Cu}-\mathrm{Ni}$ and $\mathrm{Ni}-\mathrm{Ni}$ areshown in figures 4 and table 3 .

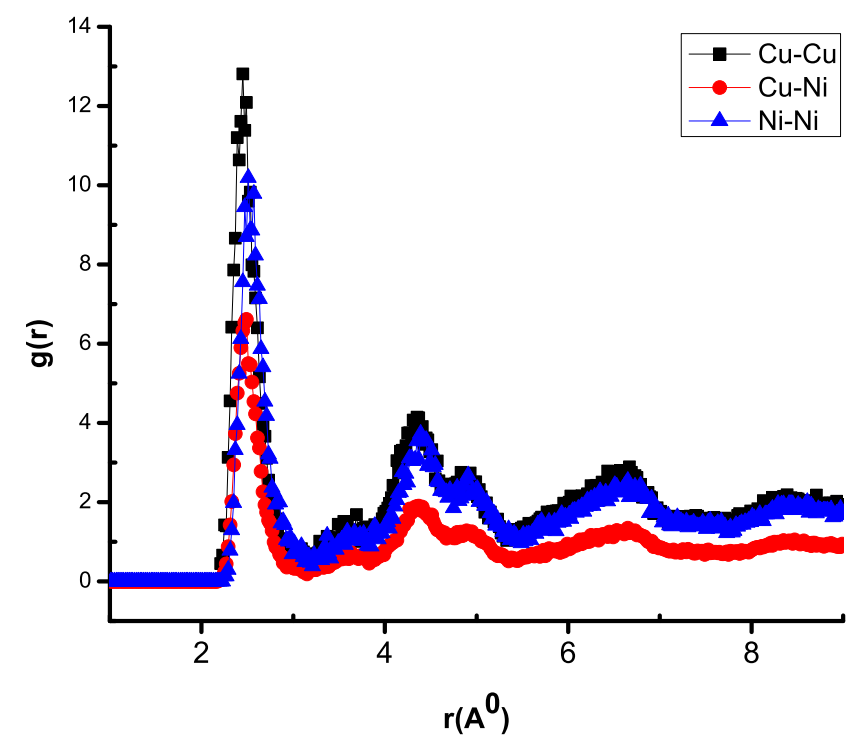

Figure 4. Radial Distribution Functions of $\mathrm{Cu}-\mathrm{Cu}, \mathrm{Ni}-\mathrm{Cu}$ and $\mathrm{Ni}-\mathrm{Ni}$ in Nanoparticles $\mathrm{CuNi}_{4000}$ at $300 \mathrm{~K}$.

Table 3. Position, Height of Radial Distribution Functions of $\mathrm{Cu}-\mathrm{Cu}, \mathrm{Ni}-\mathrm{Cu}$, $\mathrm{Ni}-\mathrm{Ni}$ in CuNi Nanoparticle with Different Atomic Numbers.

\begin{tabular}{lllllll}
\hline \multirow{2}{*}{ Nano } & \multicolumn{2}{c}{$\left(\mathbf{A}^{\mathbf{0}}\right)$} & \multicolumn{5}{c}{$\mathbf{G}(\boldsymbol{r})$} \\
\cline { 2 - 7 } & $\boldsymbol{r}_{\mathbf{C u}-\mathrm{Cu}}$ & $\boldsymbol{r}_{\mathbf{N i}-\mathrm{Cu}}$ & $\boldsymbol{r}_{\mathbf{N i - N i}}$ & $\mathbf{g}_{\mathbf{C u}-\mathrm{Cu}}$ & $\mathbf{g}_{\mathbf{N i}-\mathrm{Cu}}$ & $\mathbf{g}_{\mathbf{N i}-\mathrm{Ni}}$ \\
\hline 4000 & 2.47 & 2.49 & 2.45 & 9.447 & 6.618 & 12.815 \\
5324 & 2.47 & 2.45 & 2.43 & 9.195 & 6.325 & 12.859 \\
6912 & 2.51 & 2.45 & 2.45 & 8.830 & 6.132 & 11.258 \\
8788 & 2.53 & 2.45 & 2.43 & 9.872 & 6.407 & 11.356 \\
{$[36]$} & 2.42 & & 2.38 & & & \\
\hline
\end{tabular}

The results in figure 4 and table 3 show that nanoparticle $\mathrm{CuNi}_{4000}$ at $300 \mathrm{~K}$ (Fig. 4) has the first peak position of radial distribution function of the $\mathrm{Cu}-\mathrm{Cu}, \mathrm{Ni}-\mathrm{Ni}$ with $\mathrm{Ni}-\mathrm{Ni}$ always at dominant position. Increasing number up to 5324, 6912 and 8788, atoms showed the first peak position of radial distribution function of $\mathrm{Cu}-\mathrm{Cu}, \mathrm{Ni}-\mathrm{Ni}, \mathrm{Cu}-\mathrm{Ni}$ with trivial variables. $\mathrm{Cu}-\mathrm{Cu}$ increased from $2.47 \AA$ to $2.53 \AA$; $\mathrm{Cu}-\mathrm{Ni}$ decreased from $2.49 \AA$ to $2.45 \AA$; Ni-Ni decreased from 2.45 $\AA$ to $2.43 \AA$. The $\mathrm{Cu}-\mathrm{Cu}, \mathrm{Ni}-\mathrm{Ni}$ bonds are fully consistent with results simulation [36]. The first peak of radial distribution function $\mathrm{g}(r)$ of $\mathrm{Cu}-\mathrm{Cu}$ decreased, then, increased to $9.447 \AA$, but later dropped down to $8.830 \AA$ up $9.872 \AA, g(r)$ of $\mathrm{Cu}-\mathrm{Ni}$ decreased, next increased to $6.618 \AA$, 
then dropped to $6.132 \AA$, again rised up to $6.407 \AA$; The $g(r)$ of Ni-Ni increased from $12.815 \AA$ up to $12.859 \AA$, then decreased to $11.258 \AA$, and rised up to $11.356 \AA$. Figures shows that nanoparticle $\mathrm{CuNi}$ does not exist in distant order, in contrary, always do in near one. Increases of atomic number lead to peak of $\mathrm{Cu}-\mathrm{Cu}, \mathrm{Ni}-\mathrm{Ni}$. To confirm that a visualization method, combined with common neighborhood analysis (CNA) is used. Changes in structural unit number in the crystalline of $\mathrm{CuNi}$ nanoparticle are resulted in figure 5, table 4 .

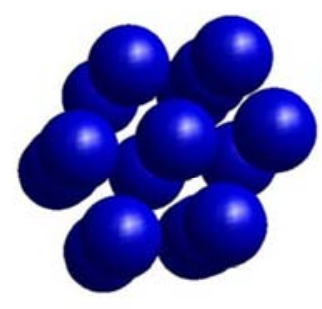

a) HCP structure

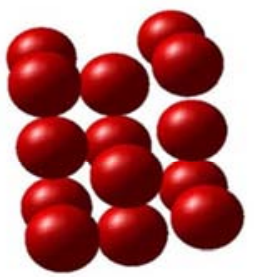

b) FCC structure c) BCC structure

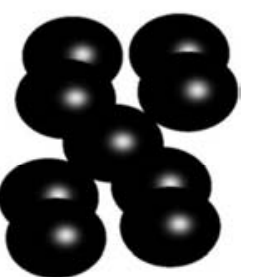

Figure 5. Structures in CuNi Nanoparticle at 300K: HCP Structure (Fig. a), FCC structure (Fig. b), BCC Structure (Fig. c).

Table 4. Table Crystalline Structure Status of CuNi Nanoparticles with Different Atomic Numbers.

\begin{tabular}{|c|c|c|c|c|c|c|c|c|}
\hline \multirow{2}{*}{ Nano particles (atoms) } & \multicolumn{2}{|l|}{$\mathrm{Cu}-\mathrm{Cu}$} & \multicolumn{2}{|l|}{$\mathrm{Ni}-\mathrm{Ni}$} & \multirow{2}{*}{$\begin{array}{l}\text { BCC } \\
\text { structure }\end{array}$} & \multirow{2}{*}{ ICO structure } & \multirow{2}{*}{ Crystals } & \multirow{2}{*}{ Amorphous } \\
\hline & FCC & HCP & FCC & HCP & & & & \\
\hline 4000 & 843 & 521 & 761 & 464 & 0 & 0 & 2589 & 1411 \\
\hline 5324 & 1079 & 702 & 987 & 640 & 12 & 10 & 3420 & 1894 \\
\hline 6912 & 376 & 537 & 334 & 488 & 0 & 39 & 1735 & 5138 \\
\hline 8788 & 1474 & 1108 & 1334 & 1039 & 0 & 0 & 4955 & 3833 \\
\hline
\end{tabular}

As resulted in Figure 5 and Table 4, nanoparticle types have 05 structures namely: FCC, HCP, BCC, Amorphous, ICO. The 4000 atoms has 03 types structures: FCC, HCP, Amorphous, among which FCC and $\mathrm{HCP}$ structure of $\mathrm{Cu}-\mathrm{Cu}$ is 843 and 521 atoms respectively; While, FCC / HCP structures of Ni-Ni is 761 / 464 atoms respectively; Crystal structure is 2589 atoms; Amorphous structure is 1411 atoms. When increasing atoms number from 4000 up to 5324, there appears five types of structures namely FCC, HCP, BCC, ICO and Amorphous, among which FCC / HCP structural number of $\mathrm{Cu}-\mathrm{Cu}$ has 1079 and 702 atoms, respectively; The FCC / HCP structure of Ni-Ni is 987 / 640 atoms respectively; BCC / ICO / crystal / Amorphous structure has 12 / 10 / 3420 / 1894 atoms respectively; Amorphous structure has 1894 atoms. Similarly, an increase of 6912 atoms leads to 04 structures namely: FCC, HCP, Amorphous, ICO; and an increase of 8788 atoms leads to 03 structures of : FCC, HCP and Amorphous. This shows that increasingnumber of atoms from 4000 up to 5324, 6912 and 8788 , results in both a rise and a fall of structures of FCC, $\mathrm{HCP}$ of $\mathrm{Cu}-\mathrm{Cu}, \mathrm{Ni}-\mathrm{Ni}$; The BCC structure only appears with 5324 atomic nanoparticle, ICO structure fluctuates in 5324 atomic nanoparticle; while 6912 atomic nanoparticle leads to a change of atomic number in crystalline state; amorphosis state also fluctuates (Table 4). Based on the results, with nanoparticles of 5324 atoms, theBCC structure, the largest number of structures (FCC, BCC, ICO and Amorphous) indicates that anappropriate atomic density leads to an increase of nanoparticle of structural number. Results also figures out a great influence of number atoms on d, $E_{\text {tot }}$, microstructure and a formation of structural types among FCC, HCP, BCC, ICO and Amorphous, mainly due to effects of size. An increase of atoms leads to a growing atomicdensity of shell layer which is more easily clustered and a formation of structural types among FCC, HC, BCC, ICO and Amorphous at shell and core layers of nanoparticle. Nanoparticles atoms 5324 serves as a basis to study the influence of temperature on nanoparticle $\mathrm{CuNi}$

\subsection{The Influence of Temperature}

Obtain nanoparticles $\mathrm{CuNi}_{5324}$ to study the influence of temperature on microstructure of nanoparticle by increasing temperature of nanoparticle from 0 up to $2000 \mathrm{~K}$, then lowering temperature from 2000 down to $1100,900,700$, 500 and 300 K. Results are shown in Figure 6.

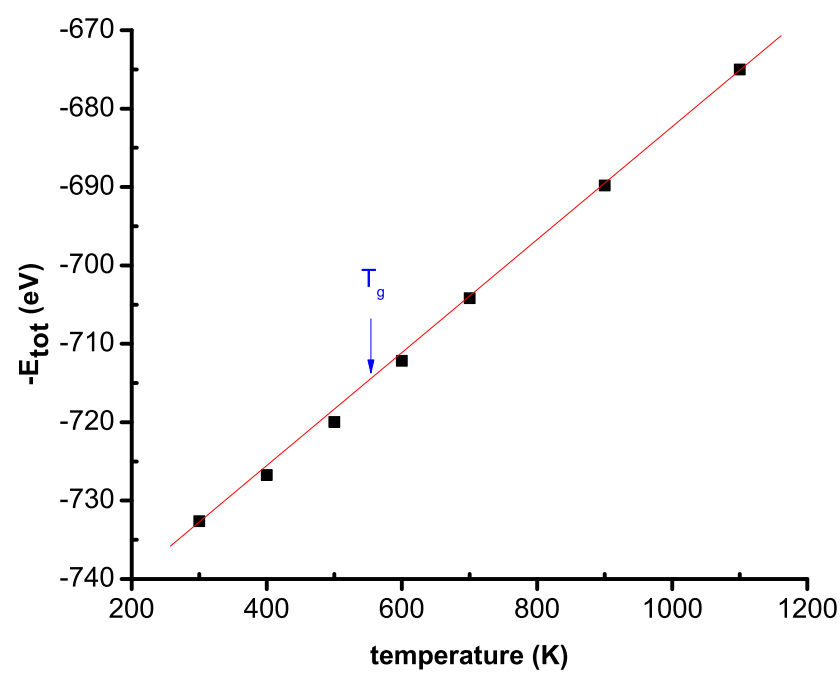

Figure 6. Relationship between $E_{\text {tot, }}$ Temperature.

Figure 6 shows that nanoparticles $\mathrm{CuNi}_{5324}$ atoms at $300 \mathrm{~K}$ has an energy of $-732.62 \mathrm{eV}$. At growingings temperatures up to $T=(400,500,600,700,900$, and 1100$) \mathrm{K}$, energy increased $E_{\text {tot }}=(-726.73,-719.97,-712.18,-717.42,-704.16$, $-689.81,-675.01) \mathrm{eV}$ respectively (Fig. 6). The results indicated a interdependence between $E_{\text {tot }}$ and $T$ (as linear rate); at temperatures of $T=(400,500,600) \mathrm{K}$, there is no linear dependence. Differently. The range from 400 to $600 \mathrm{~K}$ is the transition temperature $T_{g}$. The simulation results [35] show that $T_{g}=550 \mathrm{~K}$, with simulation, were perfectly consistent with the previous ones. To confirm this, results investigate a relationship between radial distribution function and structural unit number, as shown in Figure 7. 
a)

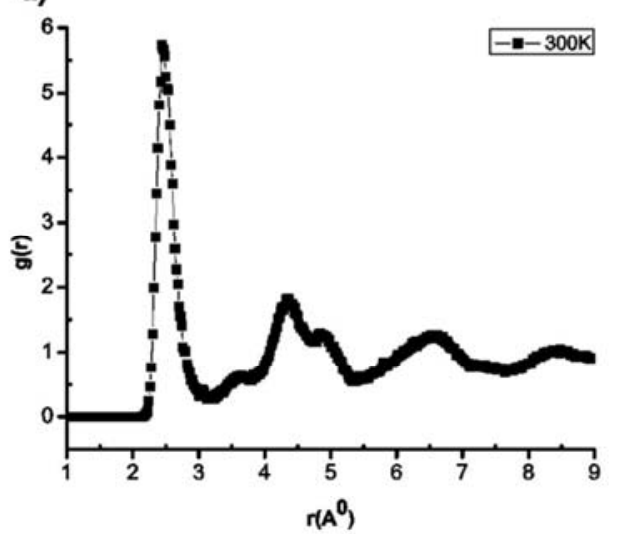

c)

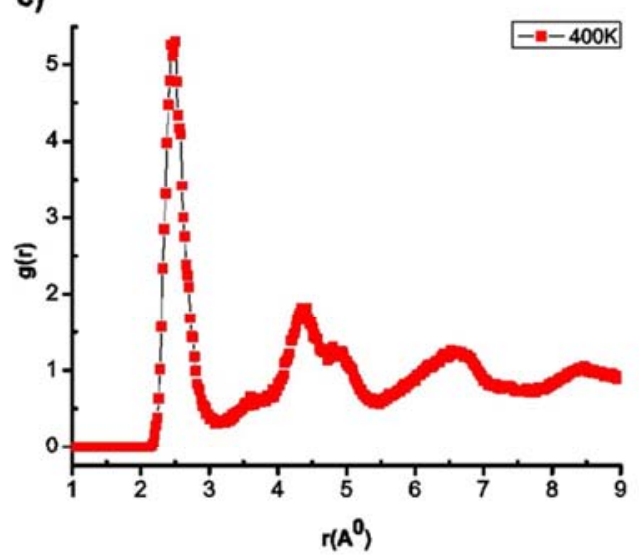

e)

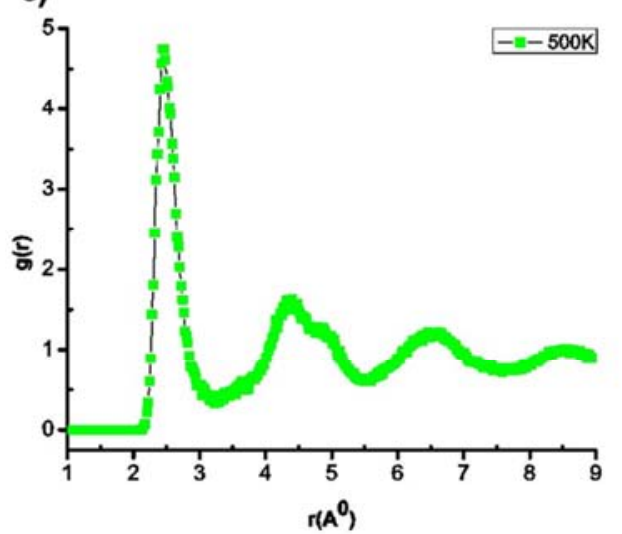

g)

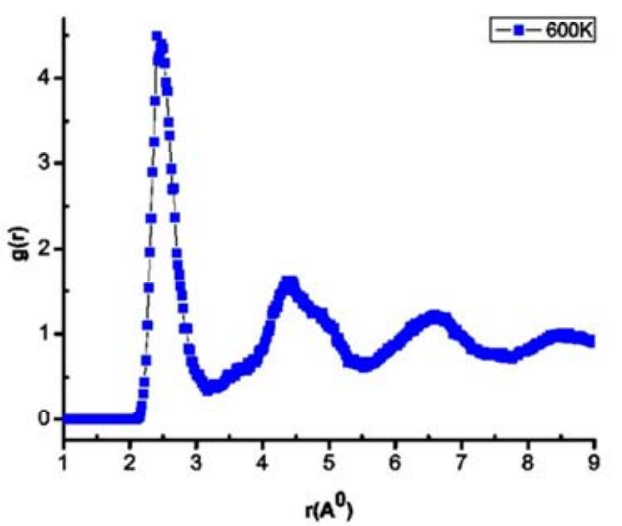

b)

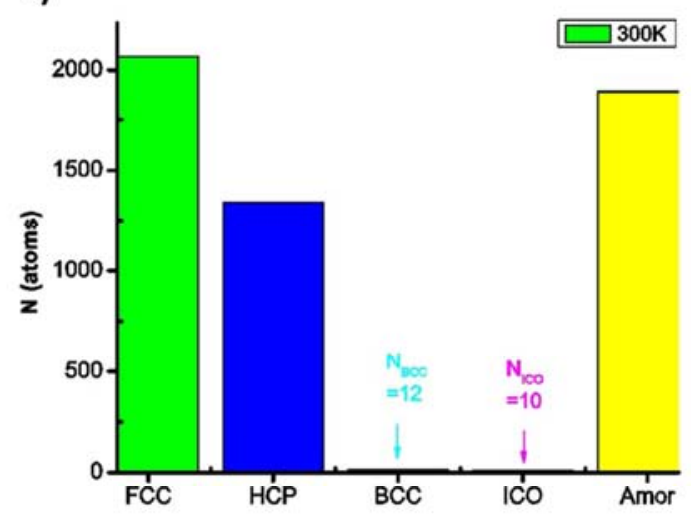

d)

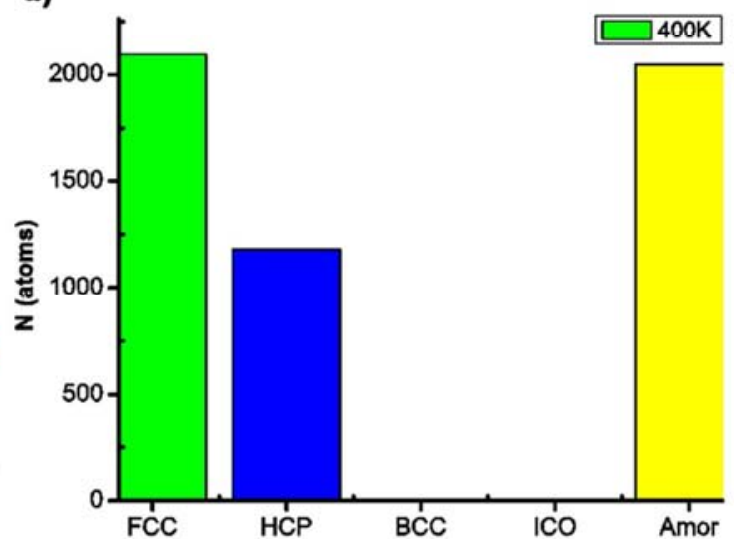

f)

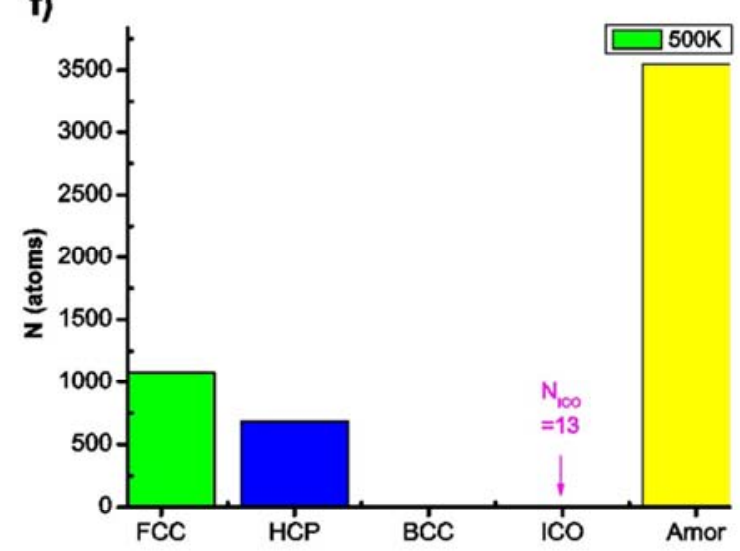

h)

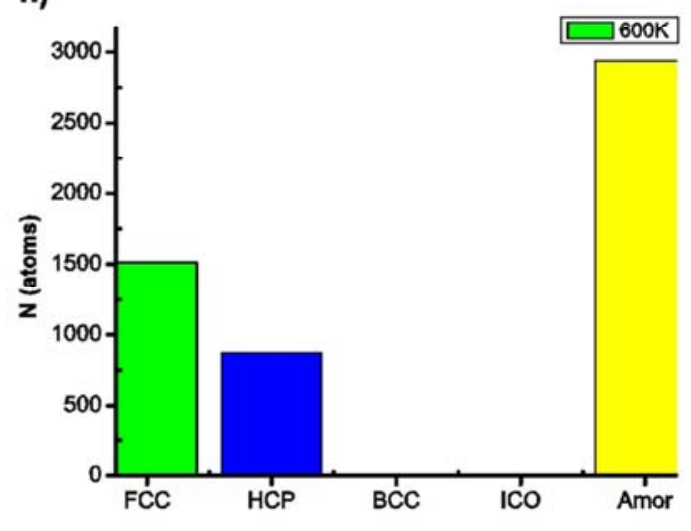


i)

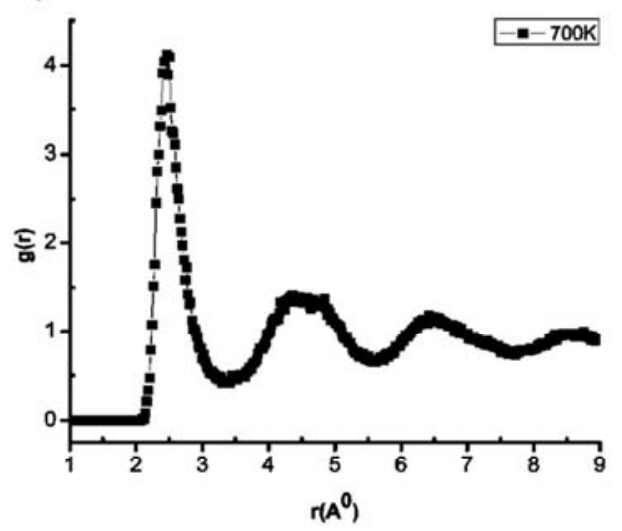

k)

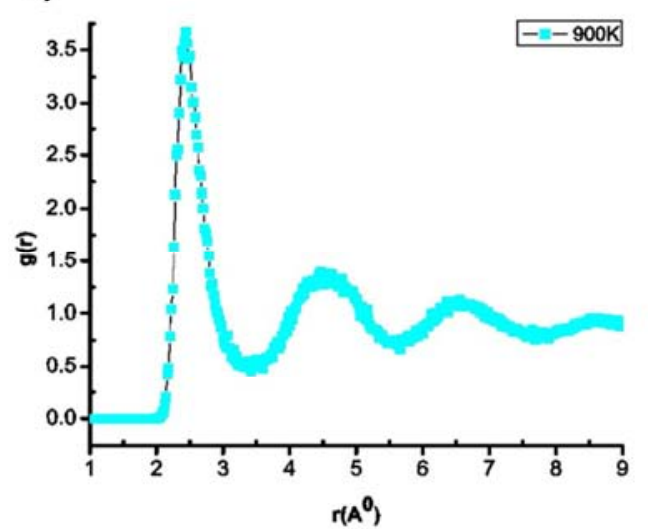

m)

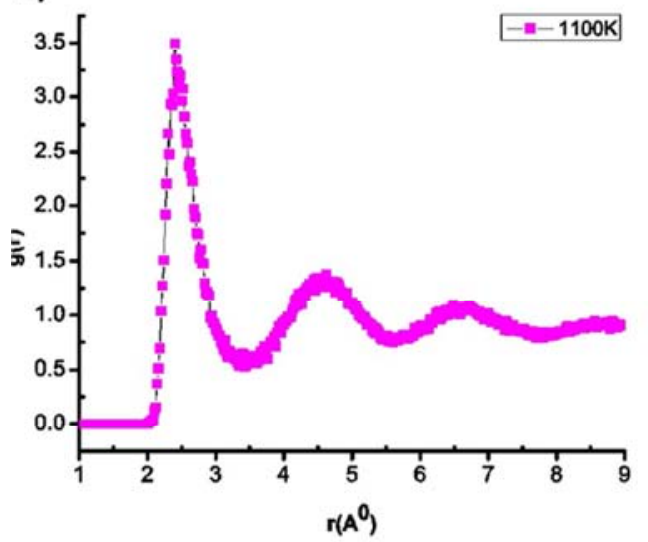

j)

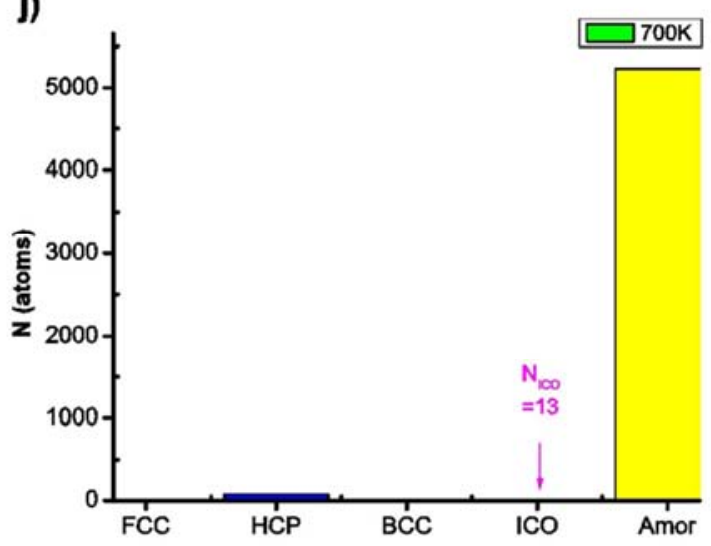

I)

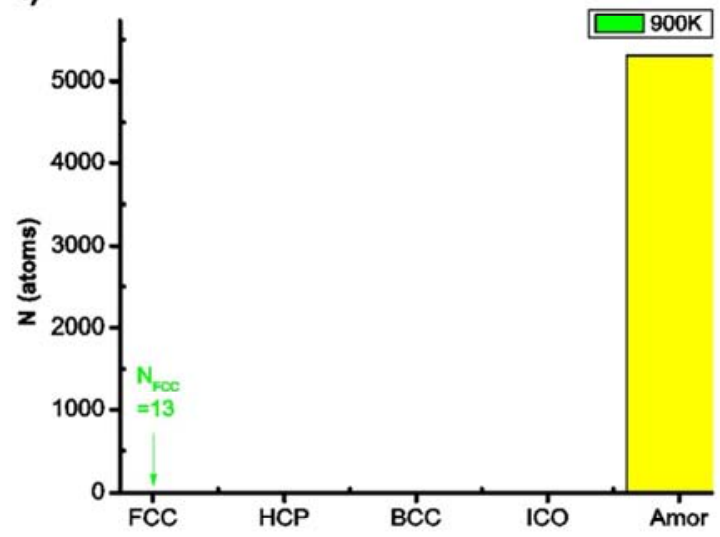

n)

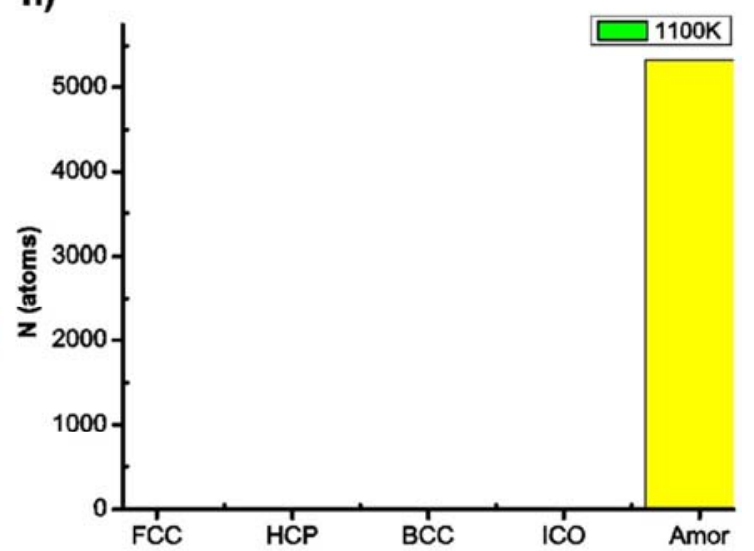

Figure 7. Radial Distribution Function of Nanoparticles CuNi ${ }_{5324}$ Atoms at Different Temperatures.

Figure 7 shows that the first peak radial distribution function of all nanoparticle $\mathrm{CuNi}_{5324}$ always prevails. At the second peak at $300 \mathrm{~K}$, there appeared 02 small: left and right shoulders at positions of $r_{21}=3.62 \AA$, and $r_{22}=3.72 \AA$ (Fig. $7 \mathrm{a}$ ), corresponding structural numbers to $\mathrm{FCC}, \mathrm{HCP}, \mathrm{BCC}$, ICO, Amor (Fig. 7b). When increasing temperature from 300 up to $400,500,600,700,1100 \mathrm{~K}$, two shoulders of the second peak of radial distribution function tends to decrease, later disappear at $600 \mathrm{~K}$ (Fig. 7g); Correspondingly, structure unit numbers of FCC, HCP decreased, amor increased, then BCC, ICO lost; At temperature increase to $700 \mathrm{~K}$, structural unit was mainly Amor (Fig. 7j), which confirmed that at temperature of $700 \mathrm{~K}$, nanoparticles $\mathrm{CuNi}$ turned into liquid state (Fig 7i), Within the temperature range from 500 to 600 $\mathrm{K}$, a loss of two shoulders of the second peak of radial distribution function appears. Combining relationship between $E_{\text {tot }}$ and $T$ (Fig. 6), phase transition temperature ranges from 500 to $600 \mathrm{~K}$ are in consistence with results simulation [35]

\subsection{Crystallization Process}

Study crystallization of nanoparticles $\mathrm{CuNi}_{5324}$ atoms at $(300,500,600,700$ and 1100$) \mathrm{K}$ after $2 \times 10^{5}$ move step (with simulation time of step number at $2.5 \mathrm{fs}$ ). The results are shown in Figure 8. 


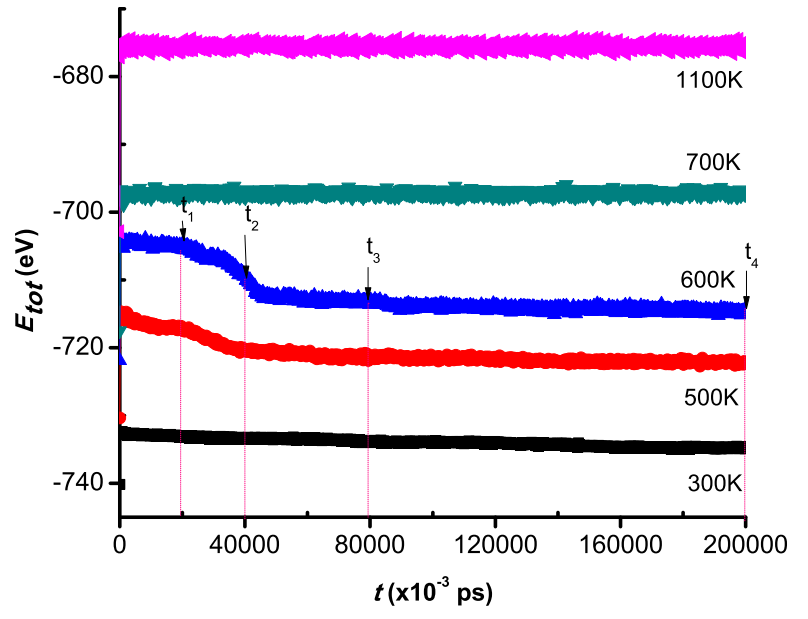

Figure 8. Relationship between Total $E_{\text {tot }}$ Energy, T Temperature of $\mathrm{CuNi} i_{5324}$ Nanoparticles after $2 \times 10^{5}$ move steps.

Figure 8 shows the total $E_{t o t}$ energy of the 5324 atomic nanoparticles at $T$ temperatures as a function of the number of moves $t_{1}=50 \mathrm{ps}$. At temperature of $600 \mathrm{~K}$ presentinging the largest crystalline phenomenon, the evidence was clear that energy $E_{\text {tot }}$ decreased suddenly after incubation times. Interestingly, at this temperature, the second drop occurred. $t_{3}=200 \mathrm{ps}$. This particularity is considered a result of significant changes in structural unit numbers in nanoparticle CuNi. When temperature drops to $300 \mathrm{~K}, E_{\text {tot }}$ a slight reduction of $t_{i}$ indicates that crystalline phase (Amorphous, crystalline) has valuable closed to samples bulk. Thereby,
$\mathrm{CuNi}$ nanoparticles, at high temperatures has high energy value and vice versa. An increases of moves step number (in correspondence to an increase of heating time of $t_{i}$ ) leads to a negligible change value of energy of nanoparticles at temperatures $T=(300,700,1100) \mathrm{K}$. It reflects that at temperature of $300 \mathrm{~K}$, nanoparticle turns to amor status, and $(700,1100) \mathrm{K}$ to liquid state, despite the unchange of microstructure of system through heating incubation. At temperatures of $500,600 \mathrm{~K}$ energy of system tends to decrease witnessing an increase of number of move steps. The energy of system drops the most in temperature range from 500 to $600 \mathrm{~K}$. At this temperature range, the greatest energy variation occurs as follows: The number of move step less than $t_{1}<20000$ steps (corresponding with heating time of $\left.t_{1}=50 \mathrm{ps}\right)$ shows energy of nanoparticles $(500,700 \mathrm{~K})$ has a constant value, while nanoparticle of $600 \mathrm{~K}$ starts to show a decrease in energy; At anincrease in number of move steps from $t_{1}$ to $t_{2}=100 \mathrm{ps}$, energies of nanoparticles $500 \mathrm{~K}$, as well as $600 \mathrm{~K}$ drop significantly. Similarly at an increase of $t_{2}$ up $t_{3}=200 \mathrm{ps}$, with $t_{4}=500 \mathrm{ps}$, energy of nanoparticles 500 $\mathrm{K}$ has a constant value, while energy of nanoparticle $600 \mathrm{~K}$ continues to decrease. This shows that within the temperature range from 500 to $600 \mathrm{~K}$ the greatest energy conversion occurs coinciding with phase $\mathrm{CuNi}$ from liquid to new crystalline states. Thus, all affirms that this area is most likely crystallization. To confirm this, investigate microstructure, unit structural numbers of nanoparticles $\mathrm{CuNi}$ at $600 \mathrm{~K}$ with heating times $t_{1}=50 \mathrm{ps}, t_{2}=100 \mathrm{ps}, t_{3}=200$ ps, $t_{4}=500$ ps through radial distribution function and CNA, as results shown at Figure 9.
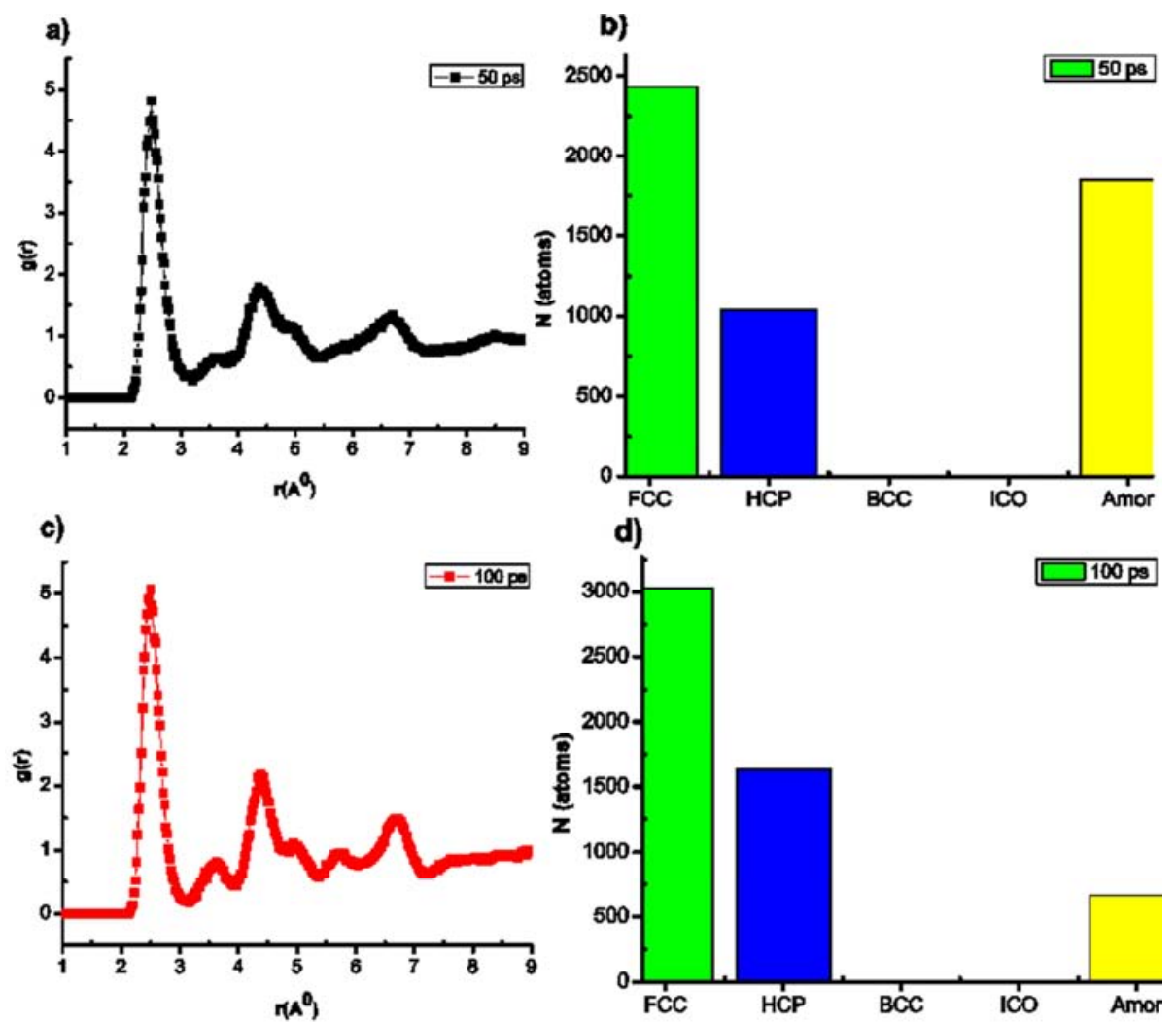

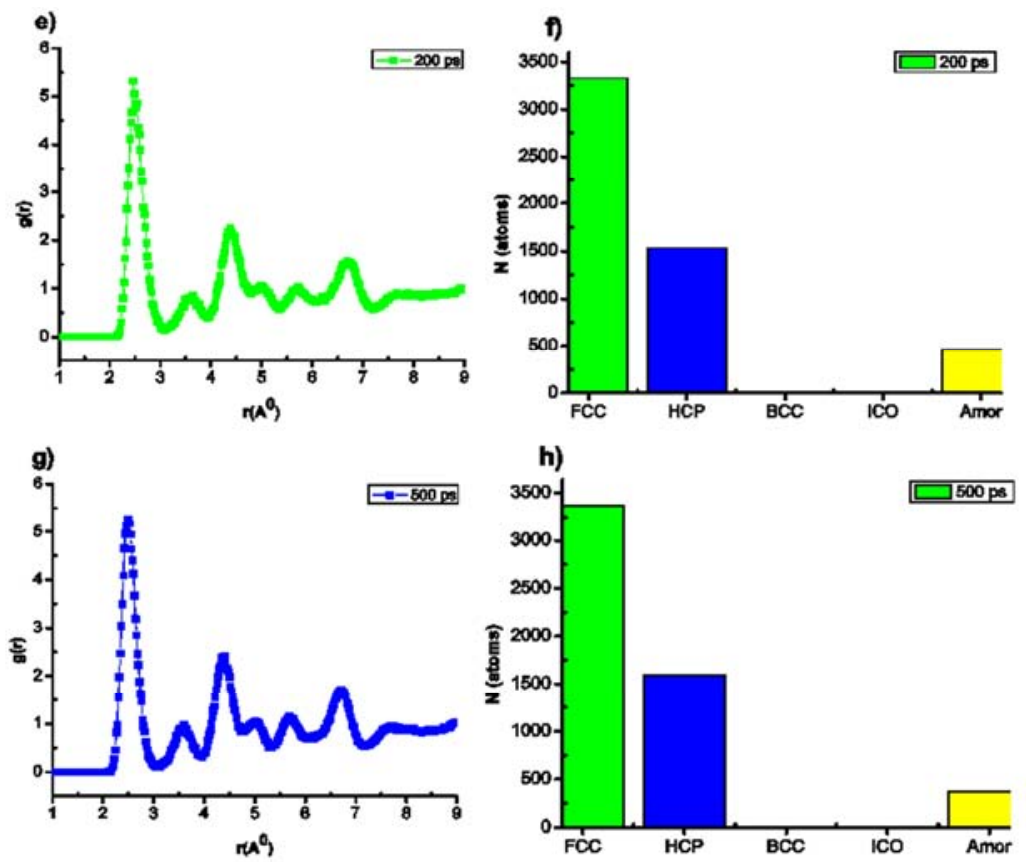

Figure 9. Radial Distribution Function of Particles CuNi ${ }_{3324}$ Atomic at $600 \mathrm{~K}$ with Different Heating Times.

Figure 9 shows that, at different heating times of $t=(50$, $100,200,500) \mathrm{ps}$, position of the first peak of radial distribution function is always dominant and has insignificant value change. This show that $\mathrm{CuNi}$ nanoparticles always exist only in near order. Besides, spacing between atoms has a constant value; The height of the first peak of radial distribution function increases with $t_{1}=50 \mathrm{ps}$. While the first peak of radial distribution function $\mathrm{g}_{1}(r)=2.48$ forms the unit number structures of FCC $=2432, \mathrm{HCP}=1038$, Amor $=$ 1854; Similarly at different heating times of $t_{2}, t_{3}, t_{4}$, increases of $t_{i}$ then $\mathrm{g}(r), \mathrm{FCC}, \mathrm{HCP}$ increase sharply, while Amor decreases dramatically. This shows that at temperature of $600 \mathrm{~K}$, after heating incubation time, density of atoms (molecules) increases sharply and crystallization occurs. To confirm this, investigate nanoparticles $\mathrm{CuNi}$ at the temperature of $500 \mathrm{~K}$ (Fig. 10, Table 4).

Table 4. Table Crystal Structure Status of Nanoparticles CuNi ${ }_{5324}$ Atoms at $500 \mathrm{~K}$ with Different Heating Times.

\begin{tabular}{llllll}
\hline Time & FCC & HCP & BCC & ICO & Amor \\
\hline $50 \mathrm{ps}$ & 1755 & 1012 & 0 & 0 & 2557 \\
$100 \mathrm{ps}$ & 2030 & 1170 & 0 & 5 & 2119 \\
$200 \mathrm{ps}$ & 2993 & 1313 & 0 & 0 & 1018 \\
$500 \mathrm{ps}$ & 3020 & 1564 & 0 & 0 & 740 \\
\hline
\end{tabular}

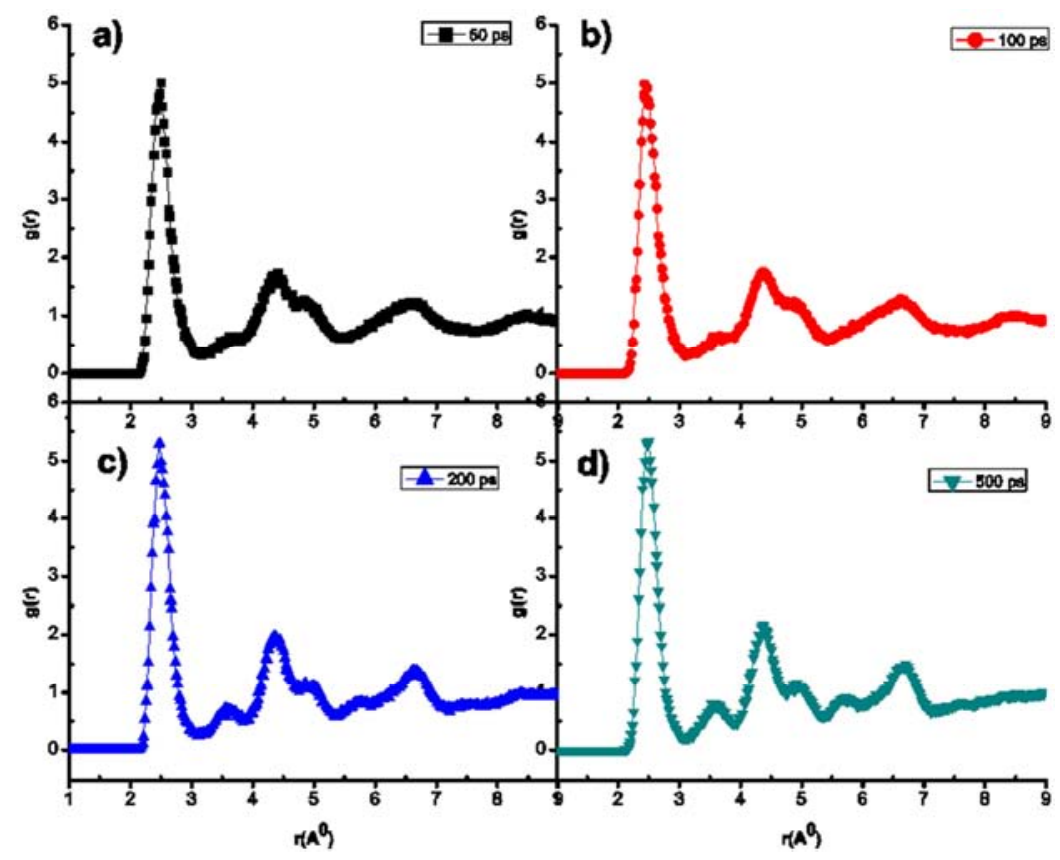

Figure 10. Radial Distribution Function of Nanoparticles CuNi ${ }_{5324}$ Atoms at $500 \mathrm{~K}$ with Different Heating Times. 
Figure 10, Table 4 shows that increasing heating time at $T=$ $500 \mathrm{~K}, \mathrm{~g}(r)$, FCC, HCP accordingly, increase sharply, despite Amor decreases dramatically. The above results show that, at temperature $T=500 \mathrm{~K}, T=600 \mathrm{~K}$, the $\mathrm{g}(r)$, FCC, HCP values increase sharply, while amor decreases seriouslyly indicating phase transition temperature of $\mathrm{CuNi}$ nanoparticles in an interval from 500 to $600 \mathrm{~K}$. Within this temperature range, $\mathrm{g}$ (r), FCC, HCP increased sharply and Amor drops seriously. A change of structure of FCC, HCP in nanoparticles $\mathrm{CuNi}$ probably results inan abnormal change around $\mathrm{g}(r)$ at $t_{i}$. In addition, another comparison between $\mathrm{g}(r)$ at temperatures of $500 \mathrm{~K}, 600 \mathrm{~K}$ (Fig. 9 and Fig. 10) shows that $\mathrm{g}_{1}(r)$ increases after $t_{i}$ increases. For small $t_{i}$ times later at (third, fourth,) picks coincide. Anincrease of $t_{i}$ leading to higher $\mathrm{g}(r)$ at $600 \mathrm{~K}$ as compared with $500 \mathrm{~K}$ indicates the greatest of crystallization at $600 \mathrm{~K}$. This confirms the influence of number of atoms, temperature and move steps number on microstructure, phase transition temperature and crystallization

\section{Conclusion}

The results of molecular dynamics simulations for ensembles containing 4000, 5324, 6912 and $8788 \mathrm{Ni}$ atoms has been obtained as follows:

An establishment of the effect of particle size d, $E_{\text {tot }}$ energy on number of atoms $\mathrm{N}$, microstructure and structural unit number of nanoparticles $\mathrm{CuNi}$ was made. The corresponding size d ranges from 13.46 to $17.49 \mathrm{~nm}$. Specifically, d-size proportional with $\mathrm{N}^{-1 / 3}$ and $E_{\text {tot }}$ linearly is proportional with $\mathrm{N}$ and results more precisely with sample bulk.

It is determined that under crystalline temperatures $T_{g}$, all nanoparticles $\mathrm{CuNi}$ are in a new state comparing the existence of structural units of: FCC, HCP, BCC, ICO, Amor and has a blend of structural units. The structure unit numbers of FCC, HCP are dominant, while the rest structures of BCC, ICO are not significant. Whether the appearance of BCC structure has an entropy increase which is indispensable for balance of the system.

From the CNA results, nanoparticles $\mathrm{CuNi}_{5324}$ ensemble is proven to have coexistences of FCC, HCP and Amorphous structures during crystallization. However, crystallization process of structural units of FCC and HCP differentiates. It is noteworthy that during heating time it always exist structural unit number of FCC, HCP, while at temperatures of 600 and $500 \mathrm{~K}$, an opposite effect on crystallization process. Finally, on the basis of BCC along with FCC, HCP structural units, amorphism one is unclear and this issue should encourage further researches.

Determine transition temperature of $T_{g}$ range from 500 to $600 \mathrm{~K}$, which is consistent with results simulation [35]

\section{References}

[1] R. D. S. Lisboa, C. S. Kiminami, J. Non-Cryst. Solids. 304, (2002), 36.
[2] Z. X. Wang, R. J. Wang, W. H. Wang, Mater. Lett. 60, (2005), 831.

[3] Duwez, P. E., Willens, R. H., Klement, W., Continuous series of metastable solid solutions in silver-copper alloys, J. Appl. Phys., 31, (1960), 1136-1137.

[4] Takayama, S., Glass formation and stability, J. Mater. Sci., 11: (1976), 164-185.

[5] Q. X. Pei, C. Lu, H. P. Lee, J. Phys. Condens. Matter 17, (2005), 1493.

[6] L. Hui, B. Xiufang, Z. Jingxiang, Mater. Sci. Eng. A 271, (1999), 116.

[7] H. R. Cong, X. F. Bian, J. X. Zhang, H. Li, Mater. Sci. Eng. A 326, (2002), 343.

[8] L. Qi, H. F. Zhang, Z. Q. Hu, P. K. Liaw, Phys. Lett. A 327, (2004), 506.

[9] M. Yan, J. F. Sun, J. Shen, J. Alloys Comp. 381, (2004), 86.

[10] M. Shimono, H. Onodera, Mater. Sci. Eng. 515, (2001), A 304-306.

[11] J. S. C. Jang, L. J. Chang, G. J. Chen, J. C. Huang, Intermetallics 13, (2005), 907.

[12] Y. L. Gao, J. Shen, J.F. Sun, G. Wang, D.W. Xing, H.Z. Xian, B.D. Zhou, Mater. Lett. 57 (2003) 1894.

[13] D. Caprion, H. R. Schober, J. Non-Cryst. Solids 369, (2003), 326-327.

[14] L. A. Marqués, L. Pelaz, M. Aboy, P. Lopez, J. Barbolla, Comput. Mater. Sci. 33, (2005), 92.

[15] Y. Shao, P. C. Clapp, J. A. Rifkin,Metall. Mater. Trans. A 27A, (1996), 1477.

[16] S. Erkoc, Phys. Rep. 278, (1997), 79.

[17] M. W. Finnis, J. E. Sinclair, Philos. Mag. A 50, (1984) 45.

[18] A. F. Voter, S. P. Chen, in: R. W. Siegel, J. R. Weertman, R. Sinclair (Eds.), Mat. Res. Soc. Symp. Proc., vol. 82, MRS, Pittsburgh, (1987), 175-180.

[19] A. P. Sutton, J. Chen, Philos. Mag. Lett. 61, (1990), 139.

[20] J. H. Shim, S. C. Lee, B. J. Lee, J. Y. Suh, Y. W. Cho, J. Cryst. Growth 250, (2003), 558.

[21] C. Kuiying, S. Xianwei, Z. Xiumu, L. Yiyi, Mater. Sci. Eng. A 214, (1996), 39.

[22] T. M. Brown, J. B. Adams, J. Non-Cryst. Solids 180, (1995), 275.

[23] Y Qi, T Çağin, Y Kimura, WA Goddard, Journal of computeraided materials design 8 (2), (2001), 233-243.

[24] Saida, J., Matsushita, M., Direct observation of icosahedral cluster in Zr70Pd30 binary glassy alloy, Appl. Phys. Lett., 79: (2001), 412-414.

[25] Zetterling, F. H. M., Dzugutov, M., Formation of large-scale icosahedral clusters in a simple liquid approach- ing the glass transition, J. Non-crystalline solids, 293-295: (2001), 39-44. 
[26] Harrop, J. D., Taraskin, S. N., Simdyankin, S. I. et al., Numerical structural analysis of the icosahedral glass and related structures, J. Non-crystalline Solids, (2001), 293-295: 556-561.

[27] A. P. Sutton and J. Chen, Philos. Mag. Lett. 61, (1990), 139.

[28] H. Rafii-Tabar and A. P. Sutton, Philos. Mag. Lett. 63, (1991), 217.

[29] Y Qi, T Çağın, Y Kimura, WA Goddard III, Physical review B 59 (5), (1999), 3527.

[30] Sutton, A. P., Chen, J., Long-range Finnis-Sinclair potentials, Philos, Mag. Lett., 61, (1990), 139-146.

[31] Doye, J. P. K., Wales, D. J., Global minima for transition metal clusters described by Sutton-Chen potentials, New J. Chem., 22, (1998), 733-744.

[32] H. Tsuzuki, P. S. Branicio, J. P. Rino, Computer physics communications 177 (6), (2007), 518-523.
[33] S. Kazanc, "Molecular dynamics study of pressure effect on crystallization behaviour of amorphous $\mathrm{CuNi}$ alloy during isothermal annealing", Physics Letters A 365, (2007) 473477.

[34] P. R. Subramanian, D. J. Chakrabarti, D. E. Laughlin, Phase Diagrams of Binary Alloys, ASM International, Materials Park, OH, (1994).

[35] Qi, Y., Cagin, T., Kimura, Y. et al., Physical review B, 59: (1993), 527-3533.

[36] T. Cagın, G. Dereli, M. Uludogan, and M. Tomak, Physical review B 5, 59 (1999-I), 3468-3473.

[37] E. L. de León-Quiroz, D. Vázquez Obregón et al., Ieee Transactions On Magnetics, 49: (2013), 4522-4524

[38] Ramazan Oguzhan Apaydin, Burcak Ebin and Sebahattin Gurmen, Metallurgical and Materials Transactions A, 47A, (2016), 3744-3752, doi: 10.1007/s11661-016-3514-7. 